\title{
LEVANTAMENTO DAS PERCEPÇÕES DEGRESSOS DE CURSOS TÉCNICOS EM AGROPECUÁRIA ACERCA DO CURRÍCULO DO CURSO
}

\author{
Clécio Henrique Limeira*, Manoella de Queiroz Rodrigues Limeira, Paloma Rodrigues Siebert, \\ Luciano de Sousa Chaves \\ *E-mail: cleciolimeira@hotmail.com \\ Instituto Federal de Educação, Ciência e Tecnologia do Pará; Universidade Federal Rural de \\ Pernambuco; Instituto Federal de Educação, Ciência e Tecnologia do Pará; Instituto Federal de \\ Educação, Ciência e Tecnologia do Pará \\ DOI: $10.15628 /$ rbept.2020.9256
}

Artigo submetido em: dez/2019 e aceito em: mar/2020

\begin{abstract}
RESUMO
O objetivo deste trabalho foi identificar as percepções acerca do currículo desenvolvido na formação de egressos de cursos técnicos em agropecuária. A técnica utilizada foi a observação direta extensiva, por meio de aplicação de questionário estruturado com questões fechadas e de múltipla escolha, além de pesquisa documental. Como resultados observamos que estágio supervisionado foi considerado fundamental pelos egressos, como forma de praticar os conhecimentos teóricos adquiridos e como porta de entrada para o mercado de trabalho. A participação em atividades de pesquisa e extensão foi considerada importante para a maioria dos egressos, servindo como estímulo e influenciando escolhas futuras dos mesmos. Foi verificado que há uma necessidade de atualização curricular para incluir temas atuais da agropecuária. Concluímos que a percepção dos egressos é importante para a construção e reconstrução dos currículos do curso técnico em agropecuária.
\end{abstract}

Palavras-Chave: Educação profissional. Ensino Técnico. Estrutura curricular. Técnico em Agropecuária.

\section{EVALUATION OF PERCEPTIONS OF TECHNICAL COURSES IN AGRICULTURE ABOUT THE COURSE CURRICULUM}

\begin{abstract}
The objective of this work was to identify the perceptions about the curriculum developed in the training of graduates of agricultural technical courses. The technique used was the extensive direct observation, through the application of a structured questionnaire with closed questions and multiple choice, as well as documentary research. As a result, we observed that the supervised internship was considered fundamental by the graduates, as a way of practicing the acquired theoretical knowledge and as a gateway to the job market. Participation in research and extension activities was considered significant for most graduates, serving as a stimulus and influencing their future choices. It was verified that there is a need for curricular updating to include current agricultural topics. We conclude that the perception of graduates is important for the construction and reconstruction of the curricula of the technical course in agriculture and livestock.
\end{abstract}

Keywords: Technical Education. Professional Education. Curricular Structure. Agricultural Technician. 


\section{REFERENCIAL TEÓRICO}

\subsection{SIGNIFICADO DE CURRÍCULO}

De maneira geral, currículo pode ser entendido como todo conhecimento que a sociedade julga necessário que os alunos aprendam no decorrer de sua vida escolar, tomando por base o significado atribuído por Sacristán (2013, p.10): "o conteúdo cultural que os centros educacionais tratam de difundir naqueles que os frequentam, bem como os efeitos que tal conteúdo provoca em receptores".

No decorrer dos tempos e dos acontecimentos históricos, o currículo vai se moldando à medida que incorpora valores sociais e interesses feitos por diversos atores envolvidos nos processos educativos (SACRISTÁN; GÓMEZ, 2000). Nesse aspecto, Sacristán (2000, p.105), propõe um modelo de interpretação de currículo baseado no cruzamento de influências e campos de atividades diferenciados e interrelacionados, composto por seis etapas de elaboração (Figura 01).

Figura 01. Proposta de interpretação do currículo de acordo com as seis etapas da elaboração.

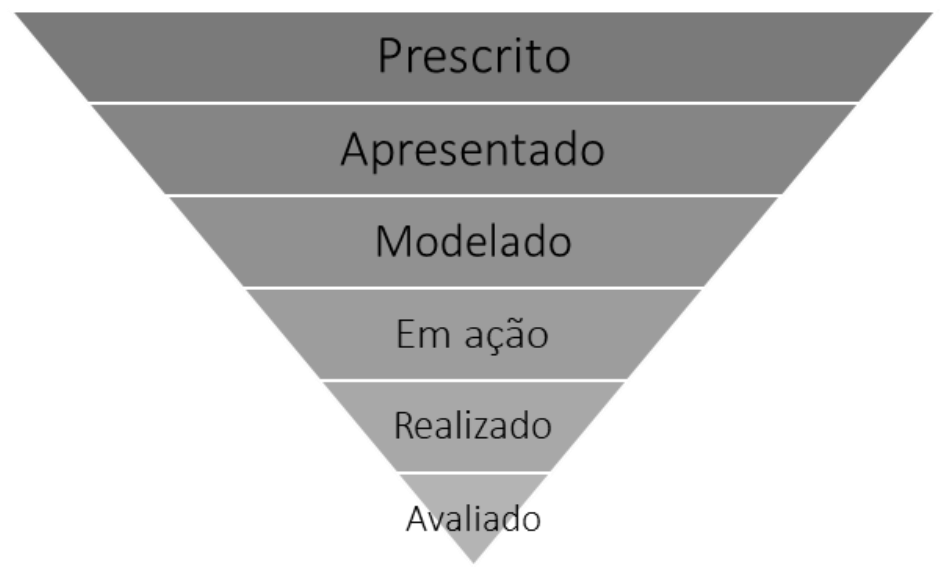

Fonte: Adaptado de Sacristán (2000)

Cada uma das etapas descritas está exposta a múltiplos agentes e diversas forças agem sobre elas, imprimindo no currículo relações de poder e visões sociais particulares e interessadas, que modelam o currículo no decorrer de mudanças históricas e políticas (BARROS et al. 2011).

\subsection{A INFLUÊNCIA DA LEGISLAÇÃO NOS CURRÍCULOS DOS CURSOS TÉCNICOS}

Na década de 1960, foi implementado o modelo escola-fazenda para os cursos técnicos em agropecuária, cujo enfoque tecnicista buscava atender ao processo de industrialização em curso (SOARES, 2004, p. 01). A filosofia desse sistema escolafazenda era caracterizada pelo "aprender para fazer e fazer para aprender", modelo 
bastante criticado por pesquisadores do assunto, uma vez que cabia aos alunos somente a parte operacional e manual da execução dos projetos, de forma alternada e sem a possibilidade de acompanhamento da sequência do processo (ALBUQUERQUE, 1984, p.133-144, apud SOARES, 2004, p.3).

Outro marco regulatório importante para os cursos profissionalizantes de maneira geral, foi a promulgação da Lei 9.394/96, a Lei de Diretrizes e Bases da Educação - LDB (BRASIL, 1996) e do Decreto 2.208/97 (BRASIL, 1997) que mudaram a forma como a Educação Profissional era ofertada no país (PIRES, 2007). A interpretação da Lei n. 9.394/96 trouxe a indicação da necessidade de construção de novas alternativas de organização curricular para o Ensino Médio:

[...] que fossem, de um lado, comprometidas com o novo significado do trabalho no contexto da globalização e, de outro, com o sujeito ativo, a pessoa humana que se apropriaria dos conhecimentos para aprimorar-se como tal, no mundo do trabalho e na prática social (MACHADO, 2005, p. 65-66).

Apesar da nova LDB ter trazido para o Ensino Médio essa possibilidade de interação entre o trabalho e a prática social, ela foi evasiva quanto à temática da relação trabalho e educação na perspectiva de uma formação integrada, deixando uma brecha para a implantação de um modelo de formação profissional desarticulada com a formação geral, através do decreto 2.208/97, com organização curriculares próprias e independentes, podendo o ensino profissional ser oferecido de forma concomitante ou subsequente ao ensino médio (AMORIM, 2016, p. 5).

O decreto 2.208/97 sofreu duras críticas e foi revogado, enfim, pelo decreto 5.154, de 23 de julho de 2004 (BRASIL, 2004; HANNECKER, 2014), retomando dessa forma a ideia de articulação entre o ensino técnico de nível médio e o ensino médio, que havia se perdido durante a vigência do decreto anterior, vindo a torna-se mais forte com a aprovação da Lei no 11.741, de 16 de julho de 2008 (BRASIL, 2008), conforme observado por Amorim (2016, p.6): "[...] a formação integrada se transforma em uma possibilidade concreta com apoio legal para ser implementada no sistema educativo brasileiro", haja vista, para o mesmo autor, ser a lei um instrumento legal mais amplo e democrático quando comparado ao decreto.

\subsection{OUTRAS FONTES DE TRANSFORMAÇÃO DO CURRÍCULO}

Para Barros et al. (2011, p. 383), "[...] a demanda dos alunos e de seus pais, a recomendação da administração superior da universidade, a interpretação dos professores acerca das necessidades dos alunos [...]" e as demandas da sociedade são fatores que também interferem na composição da matriz curricular.

Nesse sentido, Machado (2005) relata que em 1998 foi criada uma Comissão Especial para estabelecer um novo currículo para o ensino profissional, que foi responsável pela definição de vinte áreas profissionais, entre elas a agropecuária, e considerou, como proposta básica, uma certa autonomia das instituições para construção do currículo pleno, conforme expõe o próprio Machado (2005, p. 71):

[...] as escolas deveriam conciliar as demandas identificadas, sua vocação institucional e sua capacidade de atendimento. Deveria assegurar sempre a construção de currículos que, atendendo a 
princípios norteadores, propiciassem a inserção e a reinserção profissional desses técnicos no mercado de trabalho. As habilitações que, porventura, fossem criadas nas escolas, correspondentes às diversas áreas profissionais, deveriam levar em conta as demandas locais e regionais.

Todas essas interferências tem o poder de alterar o perfil dos cursos técnicos em agropecuária e das próprias instituições de ensino, podendo aumentar ou diminuir a carga horária, modificar a prática docente, implementar novas disciplinas no curso ou até mesmo sugerir e implantar novos cursos, relacionados ou não às características e aos propósitos da instituição (BARROS et al., 2011; MACHADO, 2005), expondo mais uma vez o aspecto flexível e interessado do currículo do ensino técnico profissional de nível médio.

Assim, para elencar os êxitos e possíveis falhas curriculares pensamos ser significativo realizar um levantamento com egressos de cursos técnicos em agropecuária, uma vez que estes enfrentam as adversidades e dificuldades impostas pelo dinamismo da produção agropecuária nacional. Será que eles receberam conhecimentos suficientes durante o curso para atuar como profissionais técnicos, críticos e comprometidos com o aspecto social em sua área de atuação? Essa será a principal indagação que deverá ser respondida ao fim deste trabalho. Portanto, o objetivo da presente pesquisa foi identificar as percepções acerca do currículo desenvolvido na formação de egressos de cursos técnicos em agropecuária, analisando a relação entre trabalho e o conhecimento adquirido durante o curso e a presença de fatores de mudanças que possam ter interferido no perfil de formação.

\section{METODOLOGIA}

A pesquisa teve um caráter descritivo, quali-quantitativa, usando como técnica de pesquisa a observação direta extensiva, utilizando-se um questionário estruturado (MARCONI; LAKATOS, 2010), composto por 29 perguntas fechadas e de múltipla escolha, dispostas em categorias pré-coleta e divididas em blocos relativos às informações gerais do curso, estrutura da escola e do curso, carga horária das disciplinas, áreas de afinidade, participação em projetos de pesquisa e extensão, estágio supervisionado obrigatório, mercado de trabalho e continuidade nos estudos, com posterior formação de banco de dados em planilhas e quantificação dos dados em porcentagem e demonstração dos resultados em gráficos e tabelas. Além das perguntas fechadas foi deixado um espaço aberto no final do questionário, para que os egressos deixassem sugestões para a melhoria na qualidade dos cursos técnicos em agropecuária, sendo as respostas resumidas, agrupadas por semelhança e classificadas por ordem decrescente de frequência. Também foi realizada pesquisa documental, por meio da análise de documentos públicos (normas e legislações) pertinentes ao tema.

O questionário foi elaborado utilizando-se a ferramenta online Formulários Google (Google Forms) e enviado a um grupo de egressos de cursos técnicos em agropecuária por meio de um link disponibilizado nas redes sociais e/ou endereço de email. Em seguida a formação de uma rede de contatos permitiu a distribuição do questionário para egressos de 19 escolas, das cinco regiões do país, abrangendo ex- 
alunos de todas as modalidades de ensino (integrado, subsequente ou pós-médio e concomitante) e gerando um total de 80 questionários respondidos.

\section{RESULTADOS E DISCUSSÕES}

\subsection{MODALIDADE DE ENSINO, MERCADO DE TRABALHO E ENSINO SUPERIOR}

Ao analisarmos a modalidade de ensino cursada pelos egressos e relacionarmos com a atuação no mercado de trabalho, observamos os resultados dispostos na tabela 01. Os dados demonstram um maior percentual de egressos que atuaram no mercado de trabalho entre aqueles que cursaram a modalidade concomitante e subsequente/pós-médio, quando comparados aos que estudaram na modalidade integrado. Avaliando, por exemplo, um estudo realizado na década de 80 (quando predominava o ensino concomitante e/ou pós-médio) observamos que $76,15 \%$ dos egressos do ensino agrícola estavam inseridos no mercado de trabalho, desempenhando funções relacionadas diretamente à habilitação técnica que receberam durante sua formação (FRANCO, 1987, p. 22)

Essa observação pode estar relacionada ao fato de que a modalidade concomitante era ofertada predominantemente no período de vigência da lei 9.394/96 e do decreto 2.208/97, ou seja entre 10 e 20 anos atrás, estando os egressos a mais tempo em busca de um emprego e em uma época em que a disponibilidade de profissionais da área era mais baixa. Além disso, os estudantes das modalidades subsequente/pós-médio ingressaram no curso após a conclusão do ensino médio, muitas vezes visando principalmente a inserção no mercado de trabalho, ou por não terem conseguido uma vaga no ensino superior.

Tabela 1. Percentual de egressos que atuam ou atuaram no mercado de trabalho como técnico (a) em agropecuária de acordo com a modalidade de ensino

\begin{tabular}{c|c|c}
\hline Modalidade de Ensino & \multicolumn{2}{|c}{ Atua ou atuou no mercado de trabalho? } \\
\hline & Sim & Não \\
\hline Concomitante & $90,63 \%$ & $9,37 \%$ \\
\hline Subsequente/Pós-médio & $80,95 \%$ & $19,05 \%$ \\
\hline Integrado & $62,96 \%$ & $37,04 \%$ \\
\hline
\end{tabular}

Fonte: Elaboração própria.

Já o ensino técnico integrado passou a ser ofertado nos últimos 10 anos (a partir de 2008), quando houve também um aumento significativo na oferta de vagas em cursos superiores de graduação. Assim, os egressos da modalidade integrada tiveram mais oportunidades para ingressar em uma universidade, o que pode ter contribuído para que uma parcela significativa $(37,04 \%)$ daquela modalidade não tenha atuado no mercado de trabalho. 
Além disso, ao serem questionados o porquê da escolha do curso técnico em agropecuária, $56 \%$ dos egressos responderam que identificavam-se com a área, $34 \%$ escolheram o curso por influência de terceiros (pais, familiares e/ou amigos), e $10 \%$ apresentaram respostas menos comuns como "me preparar melhor para o ENEM", "era a única alternativa no momento", "há muitas vagas no mercado de trabalho" e "para sair de casa". Esses resultados demonstram que uma parcela significativa dos egressos (44\%) não possuía vocação ou afinidade com o curso, o que pode gerar um ambiente de falta de expectativa e desinteresse na procura por alternativas de trabalho dentro da área (FERREIRA, RAITZ E VANZUITA, 2016, p. $69)$.

Com relação ao ensino superior, verificamos que $72 \%$ dos egressos que responderam ao questionário seguiram seus estudos em uma graduação após concluir o curso técnico. Os resultados obtidos estão de acordo com os encontrados na pesquisa de Ferreira, Raitz e Vanzuita (2016, p. 67), na qual 70,8\% dos egressos do curso técnico em agropecuária estavam cursando faculdade, 0 que demonstra que os mesmos têm procurado uma maior qualificação profissional, através do ensino superior, para atender um mercado de trabalho cada vez mais exigente.

Porém, ao verificar em qual curso superior os participantes da presente pesquisa ingressaram, observamos que uma parcela considerável (34\%) escolheu um curso não relacionado à formação técnica em agropecuária, o que pode estar associado à falta de identificação com a área e também à pouca oferta de emprego (FERREIRA, RAITZ E VANZUITA, 2016, p. 68). Além disso, a baixa remuneração da categoria, segundo Silvestre (2010, p. 174), também influencia a mudança de área profissional e a escolha de cursos superiores em outras áreas.

\subsection{O ESTÁGIO SUPERVISIONADO OBRIGATÓRIO}

O estágio supervisionado obrigatório é uma forma de possibilitar um maior contato dos alunos com o campo de trabalho que os esperam após a conclusão do curso. Na ótica da maioria dos egressos, o estágio curricular obrigatório supervisionado tem uma importância fundamental para sua formação (Tabela 02).

Tabela 02. Grau de importância atribuído pelos egressos ao estágio supervisionado obrigatório

\begin{tabular}{c|c}
\hline Grau de importância & Participação (\%) \\
\hline $\begin{array}{c}\text { Muito importante, pois permitiu a aplicação dos conhecimentos adquiridos na } \\
\text { prática }\end{array}$ & $78,8 \%$ \\
\hline Muito importante porque possibilitou a inserção no mercado de trabalho & $12,5 \%$ \\
\hline Importante, mas não deveria ser obrigatório & $5 \%$ \\
\hline $\begin{array}{c}\text { Pouco importante, pois não ajudou muito na complementação da formação } \\
\text { técnica. }\end{array}$ & $3,7 \%$ \\
\hline Total & $100 \%$ \\
\hline
\end{tabular}

Fonte: Elaboração própria. 
Essa importância do estágio supervisionado também é descrita por pesquisadores e estudiosos da educação, como pode ser verificado na transcrição abaixo:

Trata-se de um dos mais importantes momentos de integração dos conhecimentos trabalhados na escola a partir da prática. Jamais deve ser confundido com emprego. Mesmo ocorrendo no ambiente de trabalho é estritamente um momento de formação orientada e supervisionada, necessariamente previsto no projeto do curso. (BRASIL, 2010, p. 71).

A competência para articular o estágio supervisionado obrigatório é de responsabilidade da escola, por meio do setor ou coordenação de estágios, procurando sempre observar o interesse e a afinidade de cada aluno com a área ou setor que pretende estagiar, e pode ser realizado no próprio ambiente escolar (estágio interno), quando disponível unidades produtivas ou laboratórios, ou em ambiente externo, como fazendas, órgãos e/ou empresas públicas (EMATER, EMBRAPA) - ou privadas, empresas do setor do agronegócio, cooperativas e associações (GUERRA; BOMFIM, 2006, p.7).

\subsection{PARTICIPAÇÃO EM PROJETOS DE PESQUISA E/OU EXTENSÃO}

Quando questionados sobre a participação em projetos de pesquisa e/ou extensão durante o curso, a maior parte dos egressos apontaram que não tiveram oportunidade ou então a escola não oferecia esses tipos de projetos (Gráfico 01).

Dos egressos que responderam sim à questão anterior (seja como bolsista ou colaborador), $96,3 \%$ deles afirmaram também que essas atividades foram importantes para sua formação, e $66,7 \%$ disseram que a participação nos projetos de pesquisa e/ou extensão influenciaram as escolhas profissionais ou acadêmicas após concluir o curso técnico em agropecuária.

Gráfico 01. Participação dos egressos em projetos de pesquisa e/ou extensão durante a formação

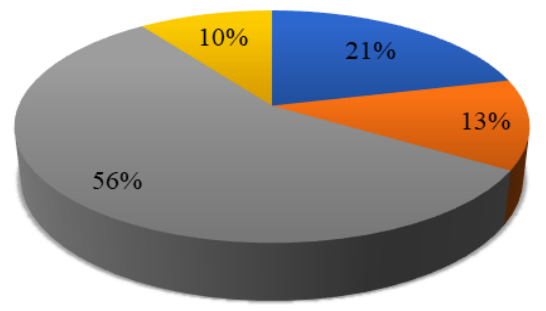

- Sim, como bolsista

- Sim, como colaborador

- Não, não tive oportunidade ou minha escola não ofercia esses tipos de projeto

Não, não tive interesse 
A pesquisa desperta no aluno uma curiosidade sobre o mundo que o cerca, de maneira que o mesmo não seja um mero reprodutor de informações e de saberes, mas que, junto com o ensino, contribua para o desenvolvimento das capacidades de interpretar, analisar, criticar, refletir, aprender e propor alternativas para problemas de natureza política, sociais, culturais e econômicas (BRASIL, 2010, p. 50).

Para Fernandes (2011, p. 75) o caráter investigativo da pesquisa aprimora a qualidade das práticas de ensino-aprendizagem de conteúdos e temas relevantes, transformando a sala de aula em um ambiente mais dinâmico com uma maior participação dos alunos no desenvolvimento das atividades, além de possibilitar uma mudança qualitativa no processo educativo por meio de uma reflexão dos professores.

\section{4 ÁREAS DO NÚCLEO TÉCNICO DESENVOLVIDAS DURANTE O CURSO}

Com relação às áreas técnicas com as quais os egressos tiveram contato durante a formação, é normal que ocorram uma maior afinidade por uma ou outra disciplina. As disciplinas de produção vegetal e animal são predominantes nas grades curriculares dos cursos técnicos em agropecuária, e isso possibilita um maior contato dos alunos com as mesmas, gerando uma certa dificuldade de conhecimento nas demais áreas do núcleo técnico (Gráfico 02).

Gráfico 02. Grau de dificuldade de conhecimento dos egressos em áreas do núcleo técnico * DFA - Defesa e Fiscalização Agropecuária

** TIPOAV - Tecnologia e Inspeção de Produtos de Origem Animal e Vegetal

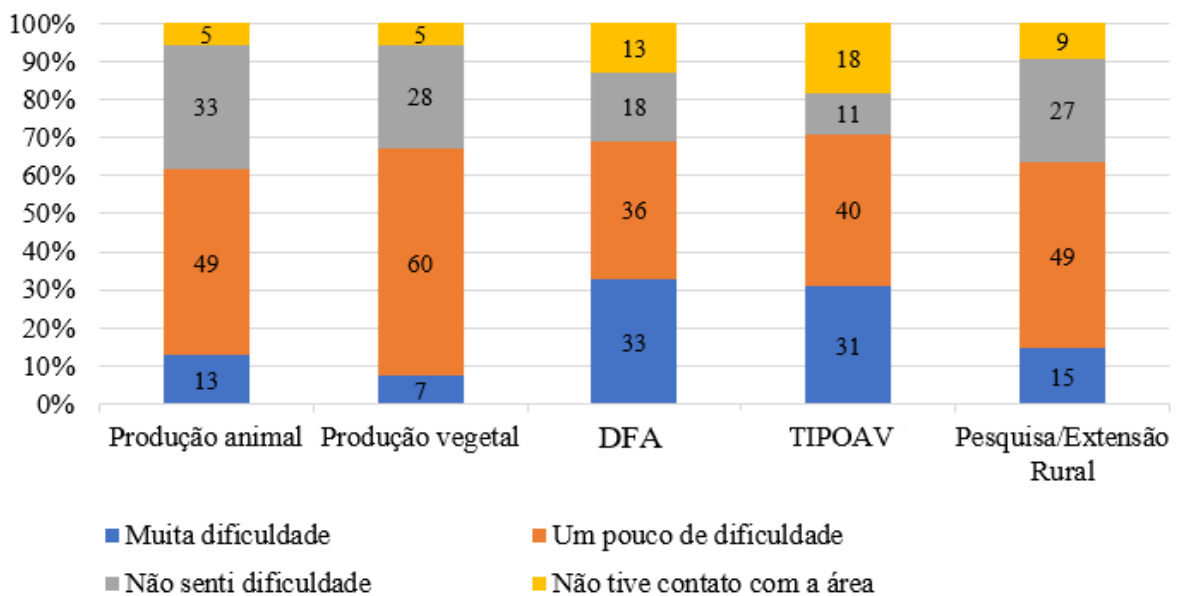

Fonte: Elaboração própria.

Dessa forma, os dados encontrados configuram a falta de contato dos egressos com áreas ou temas menos tradicionais do núcleo técnico, o que revela uma necessidade de atualização da matriz curricular dos cursos com maior frequência. Nesse aspecto, ao entrevistar docentes de um curso técnico em 
agropecuária, Barros (2009, p. 84) observou que 50\% apontam necessidade de atualização da matriz curricular, para incluir temas como bioenergia, agroecologia, normas e legislações, inovações tecnológicas, liderança, entre outras.

\subsection{SUGESTÕES DOS EGRESSOS}

Ao final do questionário, no espaço destinado às sugestões, identificamos que o principal anseio da maioria dos egressos está relacionado a um maior número de aulas práticas nas disciplinas técnicas. Porém verificamos outros pontos interessantes que devem ser considerados, como valorização profissional, maior esclarecimento acerca da profissão, maior vivência e qualificação dos professores, melhoria das estruturas físicas destinadas as aulas práticas, aumentar os incentivos para a pesquisa e extensão, incentivo ao empreendedorismo rural, maior integração entre escola e mercado de trabalho, maior adequação da grade curricular às características regionais e os novos paradigmas exigidos pela profissão e criação de um conselho de classe próprio para os técnicos em agropecuária/agrícola.

Estas sugestões retratam de forma resumida os dados encontrados pelas respostas aos questionários, e demonstram de maneira concreta os desafios e dificuldades encontrados pelos egressos ao deixarem a escola com diploma de técnico em agropecuária.

\section{CONSIDERAÇÕES FINAIS}

Procuramos por meio dessa pesquisa levantar e analisar as percepções de egressos acerca do currículo do curso técnico em agropecuária, com a finalidade de usar as experiências exitosas e não exitosas dos mesmos como ferramenta de melhoria da qualidade do curso, visando a formação de profissionais capacitados tecnicamente e comprometidos com os aspectos sociais, éticos e ambientais da região na qual estão inseridos. Os resultados encontrados nessa pesquisa nos permitiram observar que o currículo do curso técnico em agropecuária deve ser dinâmico e acompanhar as evoluções tecnológicas e de normas que se modificam ao longo dos anos.

Concluímos, portanto, que o ponto de vista dos egressos é importante para a construção e reconstrução dos currículos do curso técnico em agropecuária, devendo as instituições de ensino técnico formarem, caso não existam, comissões estruturadas e motivadas para realizarem o melhor acompanhamento de seus egressos.

\section{REFERÊNCIAS}

AMORIM, Rodrigo de Freitas. Educação Profissional e Formação Integrada do Trabalhador na Legislação Brasileira: Avanços, Retrocessos e Desafios. Revista

Brasileira da Educação Profissional e Tecnológica, v. 1, n. 10, p. 12-21, 2016. 
BARROS, Flávia Moreira Barroca. O currículo como instrumento da formação profissional do técnico em agropecuária: o caso da Central de Ensino e Desenvolvimento Agrário de Florestal - MG. 2009. 114f. Dissertação (Mestrado), Universidade Federal de Viçosa - UFV, Viçosa, MG, 2009.

BARROS, Flávia Moreira Barroca et al. O currículo do Curso Técnico em Agropecuária: subvertendo a concepção de grade curricular. Educação e Pesquisa, São Paulo, v.37, n.2, p. 375-388, mai./ago. 2011.

BRASIL. Ministério da Educação. Diretrizes curriculares nacionais para a educação Profissional técnica de nível médio em debate - Texto para discussão. Brasília: SETEC/MEC, 2010. Disponível em: http://portal.mec.gov.br/index.php?option=com_docman\&view=download\&alias=669 5-dcn-paraeducacao-profissional-debate\&category_slug=setembro-2010pdf\&ltemid=30192. Acesso em: 04 abr. 2018.

BRASIL. Lei Federal no 9.394, de 20 de dezembro de 1996. Estabelece as diretrizes e bases da educação nacional. Brasília/DF: D.O.U 22/12/1996.

BRASIL. Decreto № 2.208, de 17 de abril de 1997. Regulamenta ० § 2ํㅡ do artigo 36 e os artigos 39 a 46 da lei no 9.394, de 20 de dezembro de 1996 .

BRASIL. Decreto no 5.154, de 23 de julho de 2004. Regulamenta o § 20 do artigo 36 e os artigos 39 a 41 da lei no 9.394, de 20 de dezembro de 1996.

BRASIL. Lei no 11.982, de 29 de dezembro de 2008. Institui a Rede Federal de Educação Profissional, Científica e Tecnológica e dá outras providências. 2008. Brasilia/DF, D.O.U de 30/12/2008.

FERNANDES, Christiane Caetano Martins. A pesquisa em sala de aula como instrumento pedagógico: considerações para sua inclusão na prática pedagógica. Diálogos Educ. R., Campo Grande, MS, v. 2, n. 2, p. 74-82, nov. 2011.

FERREIRA, Danilo José; RAITZ, Tania Regina; VANZUITA, Alexandre. As trajetórias dos egressos do ensino médio integrado em agropecuária: rumo ao trabalho ou ensino superior? B. Téc. Senac, Rio de Janeiro, v. 42, n. 3, p. 54-75, set./dez. 2016. FRANCO, Maria Laura P. Barbosa. O ensino técnico agrícola do ponto de vista de seus egressos. Cad. Pesq., São Paulo (60), p. 15-27, fev. 1987.

GUERRA, Oldênia Fonseca; BONFIM, Maria do Carmo Alves do. Ensino agrícola e a inserção de mulheres e homens no mundo do agronegócio. Piauí, 2006. Disponível em: http://leg.ufpi.br/subsiteFiles/ppged/arquivos/files/eventos/2006.gt16/GT16_2006_09. PDF. Acesso em: 29 mar. 2018.

HANNECKER, Lenir Antônio. Compreensão de currículo na educação profissional: possibilidades e tensões do ensino médio integrado. 2014. 202f. Tese (Doutorado) - Universidade do Vale do Rio dos Sinos, São Leopoldo, RS, 2014.

MACHADO, Enio Rodrigues. Mudança na Formação do Técnico Agrícola no Centro Federal de Educação Tecnológica de Urutaí - GO - O Proposto e o Realizado. 2005. 115 f. Dissertação (Mestrado em Ciências Humanas) - Pontifícia Universidade Católica de Goiás, Goiânia, 2005.

MARCONI, Maria de Andrade; LAKATOS, Eva Maria. Fundamentos de metodologia científica. 7. Ed. São Paulo: Atlas, 2010. 
PIRES, Tacila. Educação Profissional: a necessária integração curricular, 2007. Disponível em: http//www.diaadiaeducacao.pr.gov.br/portals/pde/arquivos/37-4.pdf. Acesso em: 08 de março de 2017.

SACRISTÁN, José Gimeno. Saberes e incertezas sobre o currículo. Penso Editora, 2013.

SACRISTÁN, J. G.; GÓMEZ, A. I. P. Compreender e transformar o ensino. 4. ed. Tradução de Ernani F. da Fonseca Rosa. Porto Alegre: Artmed, 2000.

SACRISTÁN, José Gimeno. O currículo: uma reflexão sobre a prática. 3.ed. Tradução de Ernani F. da Fonseca Rosa. Porto Alegre: Artmed, 2000.

SILVESTRE, Ana Lúcia. A influência da educação profissional na trajetória pessoal e profissional dos egressos dos egressos do curso técnico em agropecuária - um estudo de caso do IFSULDEMINAS - Campus Machado. 2010. 184 f. Dissertação (Mestrado em Educação) - Universidade de Brasília - UNB, 2010.

SOARES, Ana Maria Dantas. Formação de técnicos em agropecuária: currículos como instrumento de políticas públicas de regulação. Anais... 27ª Reunião Anual da ANPED, p. 01-15, 2004. 